\title{
Experimental Investigation on Blast Response of Cellular
}

\section{Concrete}

(1)

(1)

\author{
Weimin Nian $^{a}$, Kolluru V.L. Subramaniam ${ }^{b 1}$, and Yiannis Andreopoulos ${ }^{c}$ \\ ${ }^{a}$ Project Structural Engineer, DeSimone Consulting Engineers, New York, NY 10011, U.S.A. \\ ${ }^{b}$ Department of Civil Engineering, Indian Institute of technology Hyderabad, Hyderabad, Telangana, \\ INDIA 502205
}
${ }^{c}$ Mechanical Engineering Department, City College of the City University of New York, New York, NY 10031, U.S.A.

\section{Abstract}

A test setup consisting of a shock-tube with an instrumented short rod is developed for investigating the blast response of cellular concrete foams. In the shock tube facility, blast pressure wave is generated by the rupture of a notched Aluminum membrane. An instrumented rod is calibrated for measuring transmitted stress from the cellular foam. Experiments are conducted on brittle cellular concrete foam, which exhibits non-linear stress-strain behavior associated with crushing of the cellular structure and subsequent densification. Crushing is initiated when the stress exceeds the crushing strength and continued crushing produces an upward concave stress-strain curve leading to densification of the material. Foams with two

\footnotetext{
${ }^{1}$ Corresponding Author: Department of Civil Engineering, Indian Institute of Technology Hyderabad, Hyderabad, A.P., 502205, India. Email: kvls@iith.ac.in, Tel: +91-40-2301-6093; Fax: +91-40-2301-6032
} 
20 different crushing strengths are evaluated. The influence of length of the foam is investigated.

21 For an applied blast pressure amplitude which is higher than the crushing strength of foam, the

22 wave structure in the foam consists of an elastic precursor wave followed by a compaction front

23 which produces crushing of the cellular structure of the material. From the experimental

24 investigation, the existence of a critical length for completely attenuating the applied blast

25 pressure wave is established. For a given blast pressure loading, when the length of foam is

26 larger the critical length, the applied blast pressure wave is transmitted as a rectangular pulse of

27 nominally constant magnitude, which is slightly higher than the crushing strength of the foam.

28 The foam is compacted without significant densification. The critical length depends on the

29 crushing strength of the foam and the blast pressure amplitude and duration. If the length of foam

30 is smaller than the critical length, there is an enhancement in the transmitted stress amplitude. If

31 the length of foam is significantly smaller than the critical length, the transmitted stress is

32 enhanced to a magnitude higher than the applied blast pressure amplitude and the compaction of

33 foam leads to significant densification of the material.

34

35 Keywords: Blast; Shock; Cellular; Foam; Attenuation.

36

\section{Introduction}

38 Cellular materials possess energy-absorbing properties and are widely used as protective 39 materials in applications such as improving crash worthiness [Gibson and Ashby 1999]. The 40 successful use of these materials in mitigating impacts has drawn the attention of structural 41 community towards the development of blast mitigation strategies. Use of sacrificial claddings 
42 when placed in the path of an incoming blast pressure wave alter the blast wave characteristics

43 and reduce the stress transferred to the structural element to mitigate the impact of a blast

44 pressure wave have been explored [Guruprasad and Mukherjee 2000]. The available information

45 in the literature is sparse and not very consistent. Some experimental evidence and results from

46 numerical simulations suggest the possibility of stress enhancement, rather than mitigation, in the

47 substrate material when foam is placed in front.

48 The available experimental evidence indicates that both flexible polymeric and rigid 49 aluminum foams produce pressure enhancement when subjected to shock loading. Shock 50 pressure loading consists of a shock front followed by constant pressure and is associated with a 51 linearly increasing impulse input with time. The pressure enhancement by foams was first shown 52 for flexible porous material; the stress transferred at the back wall due to a planar shock wave 53 reflected off the front face of the foam exceeded the pressure obtained without the porous 54 material [Monti 1970]. These findings were later confirmed by experimental studies on the 55 interaction of shock waves with very low density flexible polymeric foams; from polyurethane 56 foam [Ben-Dor 1994 and Gvozdeva 1985] and using open-celled polymeric foams [Skews 1991 57 and 1993]. The polymeric foams used in these experiments had very high porosities (in the range 58 of $90 \%$ and higher) and were able to rebound after the loading was removed. The transmitted 59 stress from the head on collision of a planar shock wave to an elastic substrate through an open 60 celled rigid porous material has also been shown to exceed the stress magnitude obtained from 61 direct shock wave incidence on the substrate [Levy et al. 1993, Kamyab et al 2010]. Experiments 62 with the use of metallic (Alumina matrix) and brittle (Silicon Carbide matrix) foams were 63 confined to studying the response at shock pressure amplitudes which do not produce significant 
64 deformation of the solid skeleton. The extension of results for metallic and brittle foams at

65 pressure amplitudes which would produce irreversible compaction, are not clear.

66 Loading associated with a blast pressure wave has a decaying pressure profile, which follows

67 the sudden pressure rise produced by the leading shock front. Blast pressure loading is of a short

68 duration and is associated with a finite impulse input. Therefore, extension of the findings from

69 shock loading to the case of transient loadings with finite impulse is not yet clear. Limited results

70 on stress amplification by soft foams for blast loading are available. In a study on the thoracic

71 visceral injury from blast loading, it was found that the transmitted overpressure from air to the

72 anechoic water chamber is enhanced significantly by a soft foam layer [Cooper et. al. 1991]. The

73 results indicated that a soft foam layer attached to substrate may produce a higher level of

74 damage in the protected object.

75 The experimental results on the use of metallic foams obtained from studies involving impact

76 have shown the benefit of using foam in providing energy dissipation [Tan et al. 2005, Reid and

77 Peng 1997]. It should however be noted that there is a fundamental difference in the nature of

78 loading associated with impact and blast pressure. In an impact, the energy delivered to a solid

79 substrate by a projectile travelling at a given velocity, is a fixed value but the stress transmitted at

80 the interface can vary depending on the materials in contact. The loading history produced by an

81 incident blast wave at different solid substrates is always the same (neglecting the effect of the

82 fluid solid interaction) but, the energy transferred to the solid substrate varies depending upon

83 the stiffness of the substrate and is larger for softer material [Subramaniam et al. 2009, Nian et

84 al. 2010].

85 Experiments involving blast loading with the use of metallic and brittle foams have been 86 confined to studying the interaction at blast pressure amplitudes which do not produce any 
87 significant change in the structure of the foam and deformations of the solid skeleton are limited

88 to elastic deformations [Ben-Dor et al. 1994, Levy et al. 1995, Standley et al. 2002]. These

89 studies were limited to understanding the change in the characteristics of the pressure wave upon

90 transmission through the porous matrix. Experimental results on the blast response of aluminum

91 foam panels, which undergo compaction showed that the addition of the foam panels increased

92 the energy and impulse transferred to a structure [Hanssen et al. 2002]. The blast pressure wave

93 obtained from an explosive charge was used. While the predictions of transmitted stress

94 considering irreversible compaction of the material indicated a decrease in transmitted pressure

95 to the face of the pendulum, these could not be verified since the applied blast pressure and the

96 pressure transmitted to the substrate were not measured in the experiments. The increase in

97 transmitted impulse was attributed to the geometric effect associated with the continuous change

98 in the shape of the initially plane panel surface into a double-curved shape.

99 The available information consisting of successful use in mitigating impact using foams 100 which undergo irreversible compaction do not provide sufficient indication about the application 101 of foam in mitigating blast loading. The blast test results available in the literature [Cooper et. al.

1021991 and Hanssen et al. 2002] are also not helpful since the stress transmitted from the foam to

103 the solid substrate, which is critical to understand the behavior of foam in blast mitigation, were

104 not measured. Careful experiments on blast response of foams obtained from experiments with 105 well-defined input blast pressure waves, which would lead to a fundamental understanding of the 106 behavior of foam, are currently not available.

107 In this study, an experimental investigation of the one-dimensional dynamic response of 108 cellular concrete foams subjected to blast pressure loading was conducted. Cellular concrete is a 109 class of brittle matrix foam, which exhibits compaction associated with crushing of structure. A 
110 shock tube was used to generate controlled blast pressure loading of different amplitudes and

111 durations. Instrumentations for measuring the blast pressure history applied at the front end

112 (loaded end) of the foam and the stress transmitted to a solid substrate through the foam

113 (transmitted stresses) were developed. Cement foams of different densities and different lengths

114 were evaluated for different blast pressure loadings. The deformation of the cement foam bars

115 after application of the blast pressure loading was also recorded.

116

117 Cellular Concrete Foam

118 The cellular concrete foam has a cementitious matrix and a cellular structure consisting of

119 large entrained porosity in the form of uniformly distributed air cells. The air cells are introduced

120 by mixing a stable, voluminous, micro-bubbled foam into cement paste. The porosity of the mix

121 is varied by controlling the volume of foam mixed into the cement paste. After setting, when the

122 cement paste gains strength, the cementitious matrix develops a cellular structure. The bubbles in

123 the foam form disconnected pore space.

124 The cellular concrete foams used in this study were made using cement paste with a water to

125 cement ratio (by mass) equal to 0.55 . The cement paste was prepared by mixing cement and

126 water in a paddle mixer. Polypropylene fibers (Stealth ${ }^{\circledR}$ e 3 micro-reinforcement, classification

127 D700/800) were also added to the cement paste. Approximately, 10 grams of fibers was used for

128 each $5 \mathrm{~kg}$ of cement paste. The foam was generated with a foam generator (shown in Figure 5.5)

129 using a commercially available foaming agent. MEARLCRETE® FOAM LIQUID produced by

130 Cellular Concrete LLC which is an aqueous concentrate of a surface-active Polypeptide-

131 Alkylene Polyol condensate, specially formulated to yield tough, stable, voluminous micro 
132 bubbled foam. The foaming agent was diluted in water at the recommended dosage and mixed 133 with air in the foam generator. The foam was then hand mixed with the cement paste and cement 134 foams with two different wet cast densities equal to $432 \mathrm{~kg} / \mathrm{m}^{3}$ and $528 \mathrm{~kg} / \mathrm{m}^{3}$ were produced by 135 varying the volume of foam added to the cement paste. Cylindrical samples with diameter equal 136 to $44 \mathrm{~mm}$ were prepared using acrylic molds. The inner surface of the mold was lined with a 137 Teflon paper. The paste with the entrained foam was poured into the mold in layers and gently 138 tapped on the sides to ensure proper placement. After 7 days, the foams were demolded and left 139 to dry in the laboratory environment (maintained at $23{ }^{\circ} \mathrm{C}$ and $50 \% \mathrm{RH}$ ). The dry densities of the 140 foam after 7 days were equal to $384 \mathrm{~kg} / \mathrm{m}^{3}$ and $480 \mathrm{~kg} / \mathrm{m}^{3}$. The porosity of the cellular solid was 141 determined using the relationship between the bulk density of the cellular material ( bulk) and the 142 density of the solid matrix ( $s)$ using the relationship, porosity $=(\mathbf{1}-$ bulk $/ \mathrm{s})$. The $\mathbf{s}$ of the 143 cementitious matrix was taken as $1400 \mathrm{~kg} / \mathrm{m} 3$ and the porosities of the foams with dry densities 144 equal to $384 \mathrm{~kg} / \mathrm{m}^{3}$ and $480 \mathrm{~kg} / \mathrm{m}^{3}$ were estimated to be $73 \%$ and $65 \%$, respectively.

145 A photograph of the cellular microstructure of a typical cement foam sample showing the 146 dispersion of air cells is shown in Figure 1. A closed-cell foam structure with disconnected 147 porosity can be identified. The walls of the porous network consist of hardened cementitious 148 material. There was no moisture in the large pores of the cellular network. After 28 days of age 149 (following casting) the quasi-static load response of the foams were obtained. Tests were 150 performed by placing the foams inside an acrylic tube with inner and outer diameters equal to 15144.5 and $50.8 \mathrm{~mm}$, respectively. The acrylic tube was used to confine the material during 152 compaction and to prevent the spalling of the material due to disintegration. The acrylic tube also 153 allowed for viewing the deformation of the specimen during the test. The acrylic tube was 154 instrumented with a strain gage to measure circumferential strains. To minimize the influence of 
155 friction in the relative motion between the foam and the tube during compaction, the cement 156 foam was wrapped with two sheets of Teflon and a low viscosity oil was placed in the gap 157 between the Teflon sheet and the inner wall of the acrylic tube. Load was applied to the foam using a steel cylinder which could slide inside the acrylic tube. The test setup with the acrylic 159 tube and steel cylinder ensured a one-dimensional state of motion and to confine the material 160 from disintegration. During the deformation, engineering strain was computed as the relative 161 displacement between the two ends of the foam divided by the original length of the foam.

\section{(a)}

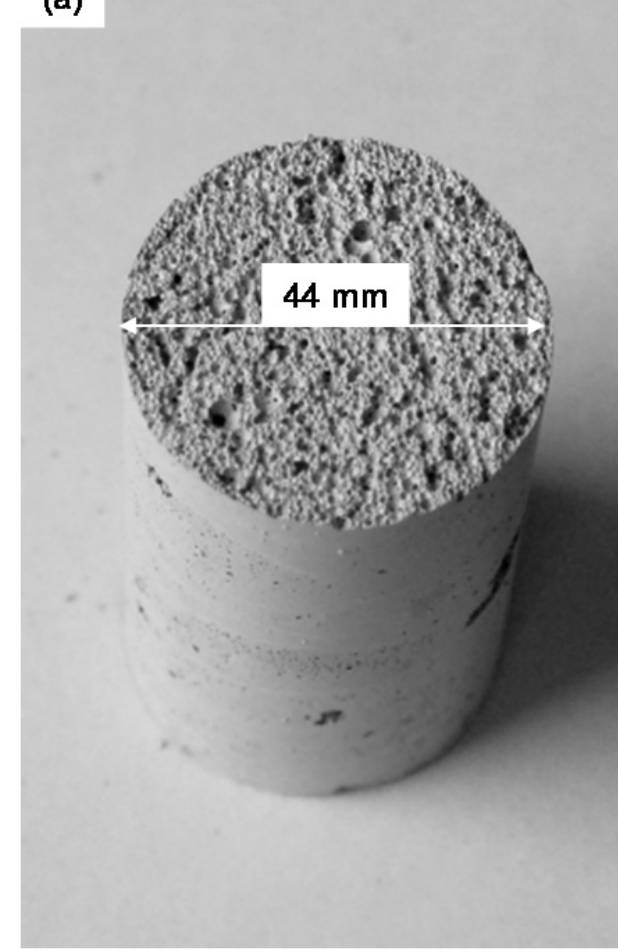

(b)

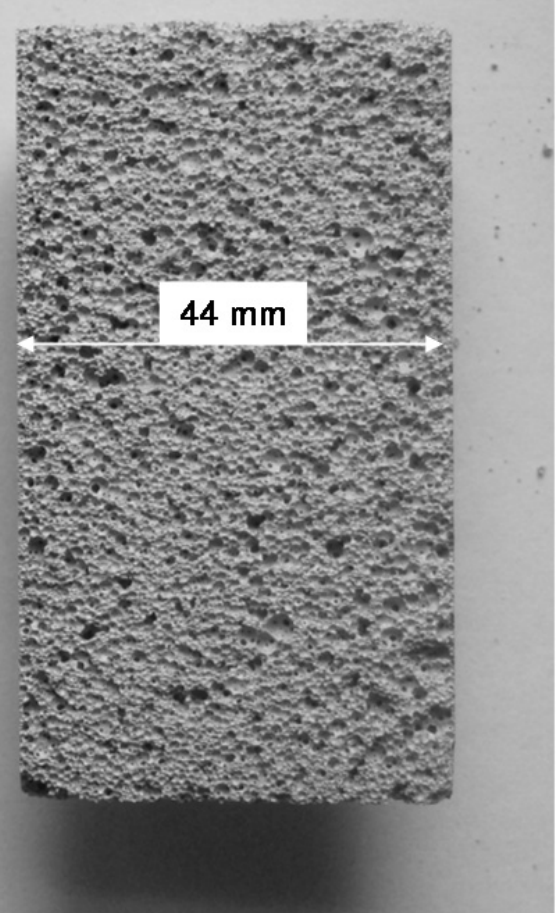

\section{Figure 1: Photographs of the cellular concrete foam sample (a) cross-section and (b) a} section along longitudinal axis

\section{Typical quasi static load response of the foams is shown in Figure 2. Three distinct regions} can be identified in a typical stress-strain curve of cellular concrete, namely the linear elastic response, the crushing plateau and the densification region. Initially, the behavior is linear elastic, with a slope equal to the Young modulus of the foam. The concave response is associated 
169 with the collapse of the internal structure and subsequent densification. The cell collapse is

170 associated with brittle crushing of the cell walls. The collapse of cells and the densification of

171 material produce a gradual upward concave stress-strain response with increasing slope as more

172 cells are compacted. It should be noted that while engineering strain is calculated using the

173 overall shortening of the entire length of foam, the local deformation in the material is non-

174 uniform in the concave part of the load-response. Initially, the cell collapse progresses at roughly

175 constant load where there is a large increase in strain associated with a small increase in stress,

176 giving a stress plateau. Cell collapse continues until the opposing walls in the cells meet and

177 touch, when densification causes the stress to increase steeply and approach that of the intrinsic

178 material. The contribution of gas pressure to the measured strength properties was found to be

179 insignificant and can be neglected [Nian et al. 2015, 2016]. For the measurements over the range

180 of compaction evaluated in the study, the strains measured from the acrylic tube were

181 insignificant. For the level of compaction considered in this study, the compaction is achieved at

182 the expense of reduction of entrained porosity in the cellular structure. The compaction of the

183 material, resulting in compression of the internal pore structure of the cementitious matrix, has

184 not been considered in this study. 


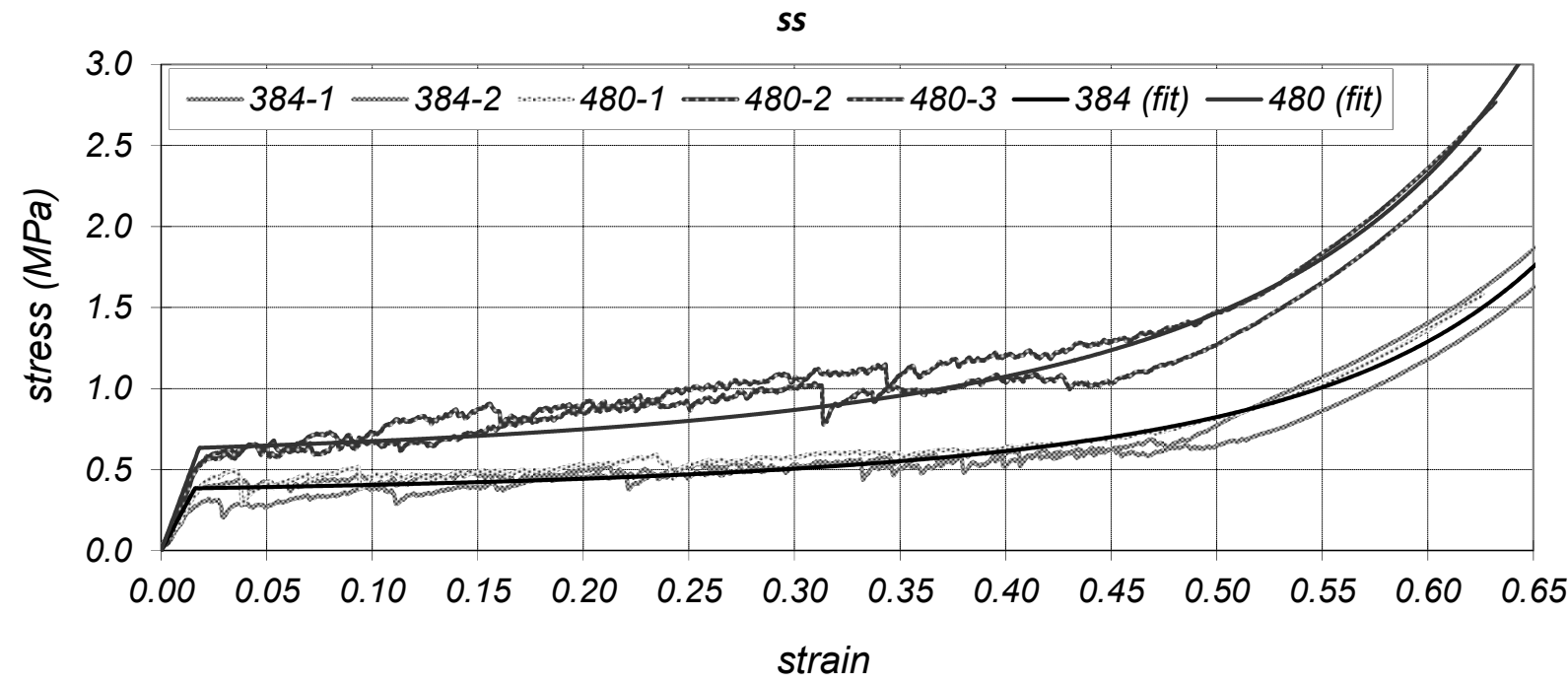

187

188

189

190

191

192 parameters given in Table 1.

193

$\sigma=\left\{\begin{array}{l}E \varepsilon \quad \quad \varepsilon \leq \varepsilon_{p o} \\ \sigma_{p o}-A E\left(1-\varepsilon_{p o}\right)^{\alpha}+A E(1-\varepsilon)^{-\alpha}\end{array}\right.$ $\mathcal{E}>\varepsilon_{p o}$

194 where E is the Young's modulus, Po is identified as the crushing strength and it marks the end

195 of the linear elastic behavior, Po is the strain corresponding to $\mathrm{Po}_{\mathrm{o}}\left(\mathrm{Po}_{\mathrm{Po}} / \mathrm{E}\right)$, is a constant

196 greater than zero and $\mathrm{A}$ is a material constant. The fitted equation is shown in Figure 2 for 197 comparison. The non-linear elastic response is initiated when the stress exceeds the crushing 198 strength of the material, Po. The average crushing strength of cellular concrete increases with an 199 increase in the dry density of the cellular concrete; the crushing strength of cellular concrete with 200 dry densities equal to $384 \mathrm{~kg} / \mathrm{m}^{3}$ and $480 \mathrm{~kg} / \mathrm{m}^{3}$ are equal to $0.384 \mathrm{MPa}$ and $0.63 \mathrm{MPa}$, 201 respectively. 
Table 1: Parameters used for the fitted curves in Figure 2

\begin{tabular}{|c|c|c|c|c|c|}
\hline $\begin{array}{c}\text { Density } \\
\mathrm{kg} / \mathrm{m}^{3}\end{array}$ & $\begin{array}{c}E \\
\mathrm{MPa}\end{array}$ & $A$ & po & $\begin{array}{c}p o \\
\mathrm{MPa}\end{array}$ & \\
\hline 384 & 24 & $1 / 350$ & 0.016 & 0.384 & 2.9 \\
$( \pm 4 \%)$ & $( \pm 9 \%)$ & $( \pm 35 \%)$ & $( \pm 12 \%)$ & $( \pm 12 \%)$ & $(10 \%)$ \\
\hline 480 & 35 & $1 / 250$ & 0.018 & 0.63 & 2.8 \\
$( \pm 3 \%)$ & $( \pm 5 \%)$ & $( \pm 25 \%)$ & $( \pm 6 \%)$ & $( \pm 6 \%)$ & $(10 \%)$ \\
\hline
\end{tabular}

A shock-tube was used for generating last pressure waves. The stress transmitted from the

207 cellular concrete foam was measured using an instrumented short rod. During a typical test, the 208 cellular concrete sample was attached in front of the instrumented short rod and blast pressure 209 loading was applied on the front end of the foam sample while the transmitted stress from the $\mathbf{2 1 0}$ back face of the sample was measured. Pressure transducers were installed in the shock tube

211 along the path of the blast pressure wave to measure the applied pressure. Experiments were 212 performed to determine the following: (a) the transmitted stress to a solid substrate as a function 213 of the applied blast pressure loading; and (b) the deformation of cement foams due to loading 214 from the blast pressure wave.

216 Shock tube for generating blast pressure waves

217 A schematic sketch and a photograph of the test facility are shown in Figure 3 . The shock 218 tube consists of a high pressure section (driver section) which is separated from the low pressure 219 section (driven section) by a diaphragm. The shock tube has a circular cross-section and is 220 entirely made of stainless steel. The driver section is $1.3 \mathrm{~m}$ in length and the inner and outer 221 diameters are equal to $8.9 \mathrm{~cm}$ and $12.6 \mathrm{~cm}$, respectively. The driver section is fitted with a screw- 
222 driven piston at the back end, which allows for varying the length of the pressurized part of the 223 driver section. The back flange of the driver section is fitted with a threaded rod through its 224 center, which is attached to a steel cylinder with a diameter equal to $8.9 \mathrm{~cm}$. Grease is applied in 225 the gap between the steel cylinder and the inner surface of the driver section to allow smooth motion of the cylindrical piston and to seal any gaps between the inner surface of the driver

227 section and the cylindrical piston. The driven section is $3.3 \mathrm{~m}$ in length and the inner and outer 228 diameters are equal to $4.5 \mathrm{~cm}$ and $7.2 \mathrm{~cm}$, respectively. Pressure ports are machined at different 229 locations along the length of the driven section for mounting pressure transducers. Pressure 230 transducers are placed flush with the inner surface of the tube. The driven section $(4.5 \mathrm{~cm}$ 231 diameter) is connected to the driver section $(8.9 \mathrm{~cm}$ diameter $)$ with a $20 \mathrm{~cm}$ long nozzle. The 232 diameter decreases smoothly from $8.9 \mathrm{~cm}$ to $4.5 \mathrm{~cm}$ over the length of nozzle. The nozzle is used 233 to accelerate and increase the Mach number of the flow.

234

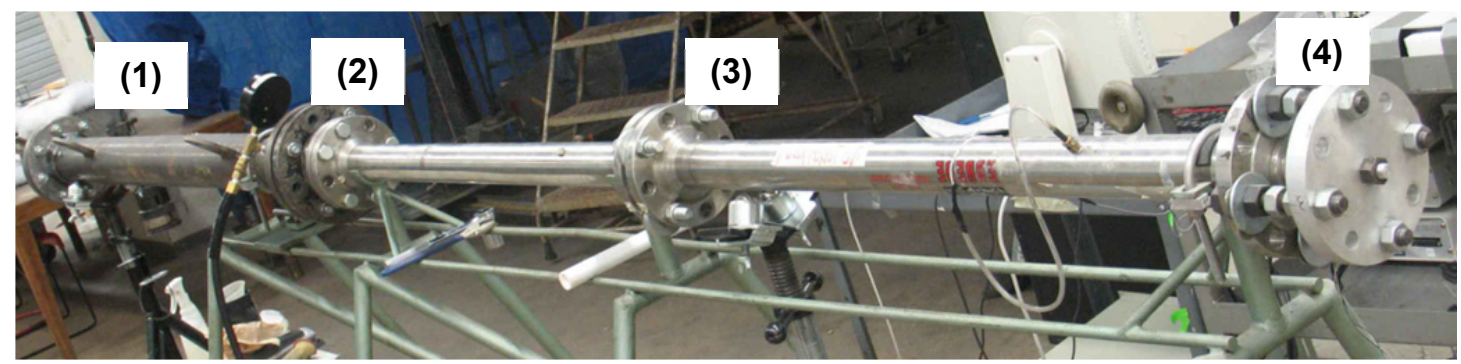

(a)

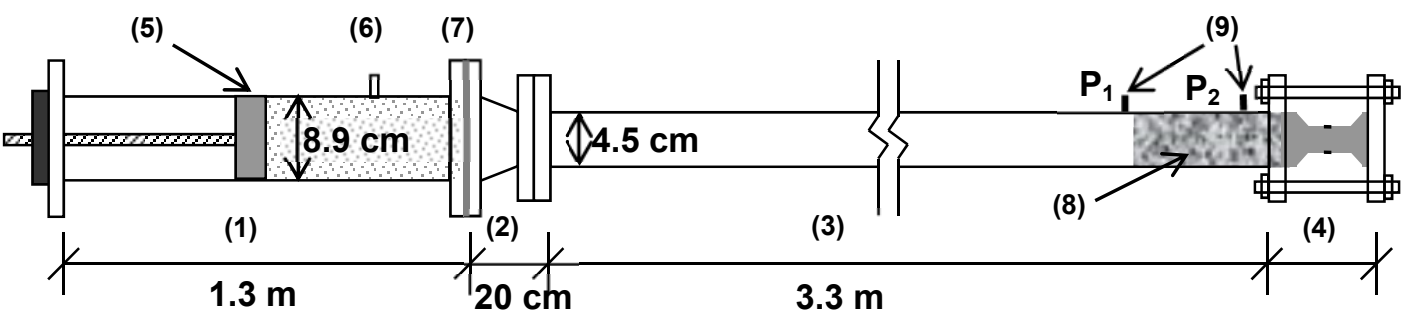

(b) 
Figure 3: Shock tube test facility: (a) photo and (b) schematic diagram. 1) driver section; 6) high pressure gas inlet; 7) diaphragm coupling; 8) cement foam sample; 9) pressure transducers $P_{1}$ and $P_{2}$.

\section{Blast pressure wave generation}

In a typical shock tube, the pressure wave is generated by the rupture of a diaphragm which is pressurized on one of its faces. The propagation of the different waves after the rupture is

247

248

249

250

251

252

253

254

255

256 257 the shock front, catch up with the shock front, a blast pressure wave is generated. An incident

258

259

260

261 262

usually presented using an X-t diagram, as shown in Figure 4. Shock waves are generated by the sudden rupturing of the diaphragm as the pressure difference between the driver and the driven sections reaches a critical value. A compression wave generated by the sudden rupture travels downstream into the driven section and rapidly steepens to form a shock front. Simultaneously, a set of rarefaction (expansion) waves travel back into the driven section, reflect at the back end of the driven section as rarefaction waves and travel downstream in the same direction as the incident shock wave. According to Prandtl's relation, the sum of the particle velocity and local wave speed in the post shock flow is higher than the shock wave speed [Courant and Friedrichs 1999]. Thus, the sound speed at which the disturbance propagates in the post-shock flow is higher than the shock wave speed. When the reflected rarefaction waves, which travel faster than blast wave consists of a leading shock front immediately followed by expansion waves, resulting in a decreasing pressures profile. The parameters, such as, the amplitude and the duration of the blast wave at the end of the driven section are controlled by varying the lengths of the driver and the driven sections and the pressures inside each section. 
267

268

269

270

271

272

273

274

275

276 277 placed close to the target end in the driver section of the shock tube. Different blast loads with 278 pressure amplitudes ranging from 0.5 to $1.5 \mathrm{MPa}$ and duration in the order of several milli279 seconds (ms) were generated. one of the faces of the diaphragm to ensure that it opened completely upon rupture. The initial pressure in the driver section at which the diaphragm ruptures was controlled by varying the depth of the notch in the diaphragm. Diaphragms made of Aluminum 6061-T6 with two perpendicular notches which intersect at the center, were used. The thickness of the diaphragm was equal to $1.6 \mathrm{~mm}$ and notches with different depths ranging from $0.8 \mathrm{~mm}$ to $1 \mathrm{~mm}$ were machined to obtain blast pressure waves with different amplitudes. The length of the driver section was adjusted by moving the piston within the driver section, to obtain the desired blast pressure characteristics. Compressed Helium was used for the high pressure gas in the driver section as it produces blast pressure waves of shorter duration when compared to air (or nitrogen). Pressure loading produced by the blast wave was measured using pressure transducers,
Blast wave at time $t_{1}$

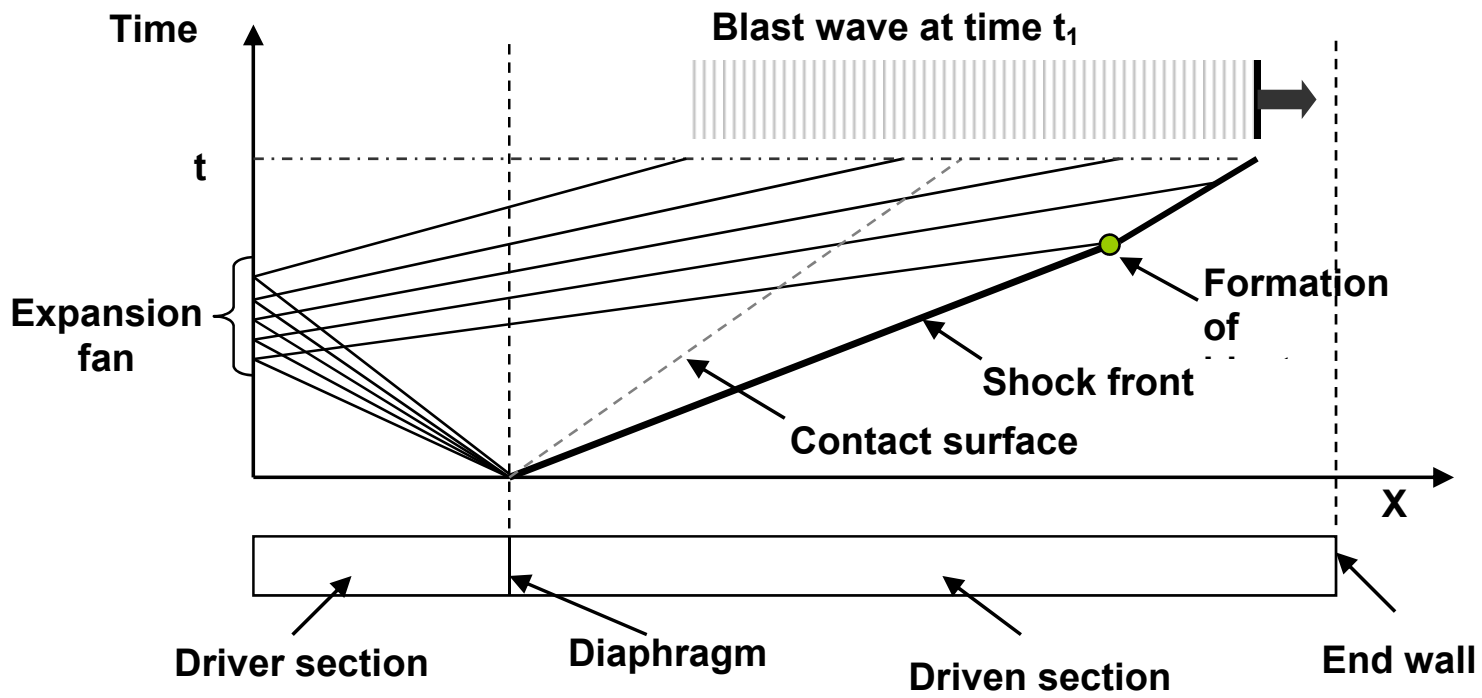

Figure 4: Formation of a blast pressure wave in the shock tube 
The shock tube facility provides the ability to control the pressure associated with the blast

281 waves allows for a fundamental evaluation of the blast response of foams and also the

282 determination of the material properties under high rates of loading. Such a facility offers a 283 significant advantage in conducting blast studies when compared with the conventional methods 284 which employ uncontrolled blast source from an explosive charge. In addition, the use of a shock 285 tube allows for evaluating the material behavior without the interfering effects of debris.

286

\section{Setup for measuring transmitted stress}

An instrumented short rod with a stepped diameter was used for measuring the transmitted

289

290

291

292

293 provides a higher sensitivity (hence better signal to noise ratio) in measurements [Tan et al.

294 2005]. A short rod was used to overcome the limitation of length in the conventional Hopkinson

295 pressure bar arrangement. In the conventional setup, the length of the pressure bar determines the 296

297 for reflection of the transmitted wave from the back end of the rod. For recording blast pressure 298 signals with durations on the order of $10 \mathrm{~ms}$, the length of the rod required in such a setup would 299 be excessive (on the order of 25 meters) and hence, impractical.

In the short stepped rod, multiple reflections of stress waves form both ends and at the edges 301 would occur within the duration of an applied stress pulse and the stress at a given location 
302 would be the result of superposition of the applied stress pulse and the reflected waves. The

303 reflected waves would produce oscillations in the measured stress on a time scale associated with

304 the time of travel for the waves over the length of rod. For a short rod, the time scale associated

305 with the oscillations can be made significantly smaller than the time scale associated with the

306 applied loading. In this case, the applied pressure can be separated by filtering the high

307 frequency variations associated with the wave reflections.

308

In the experimental setup, the overall length of the instrumented short rod was selected such

309 that the time scale associated with the oscillations was on the order of $10-100 \mathrm{~s}$, while the blast

310 pressure duration was in the range of $10 \mathrm{~ms}$. The diameter of instrumented short rod was

311 decreased from $44.5 \mathrm{~mm}$ at the loaded end to $19.2 \mathrm{~mm}$ at the measuring locations. The validity of

312 using measured strain from the instrumented short rod by separating the contributions of the

313 oscillations produced by reflections was confirmed using numerical simulation. In addition, the

314 instrumented rod was calibrated against applied blast pressure signals. The transmitted stress

315 recorded by the instrumented short rod when a blast wave is directly applied on the face of the

316 rod was used for this purpose.

317 A schematic sketch of the instrumented short rod is shown in Figure 5. The instrumented

318 short rod fitted perfectly inside the driver section of the shock tube and was fixed to a large

319 aluminum plate at the other end. The aluminum plate was connected to the end flange of the

320 shock tube using four threaded bolts. The sample to be tested rested against the face of the short

321 rod. Four strain gages are placed 90 degrees apart around the perimeter in the middle of the short

322 rod. To reduce the influence of the bending effect, misalignment of the fixture and asymmetric

323 loading, the average of the four strain gages was recorded. 


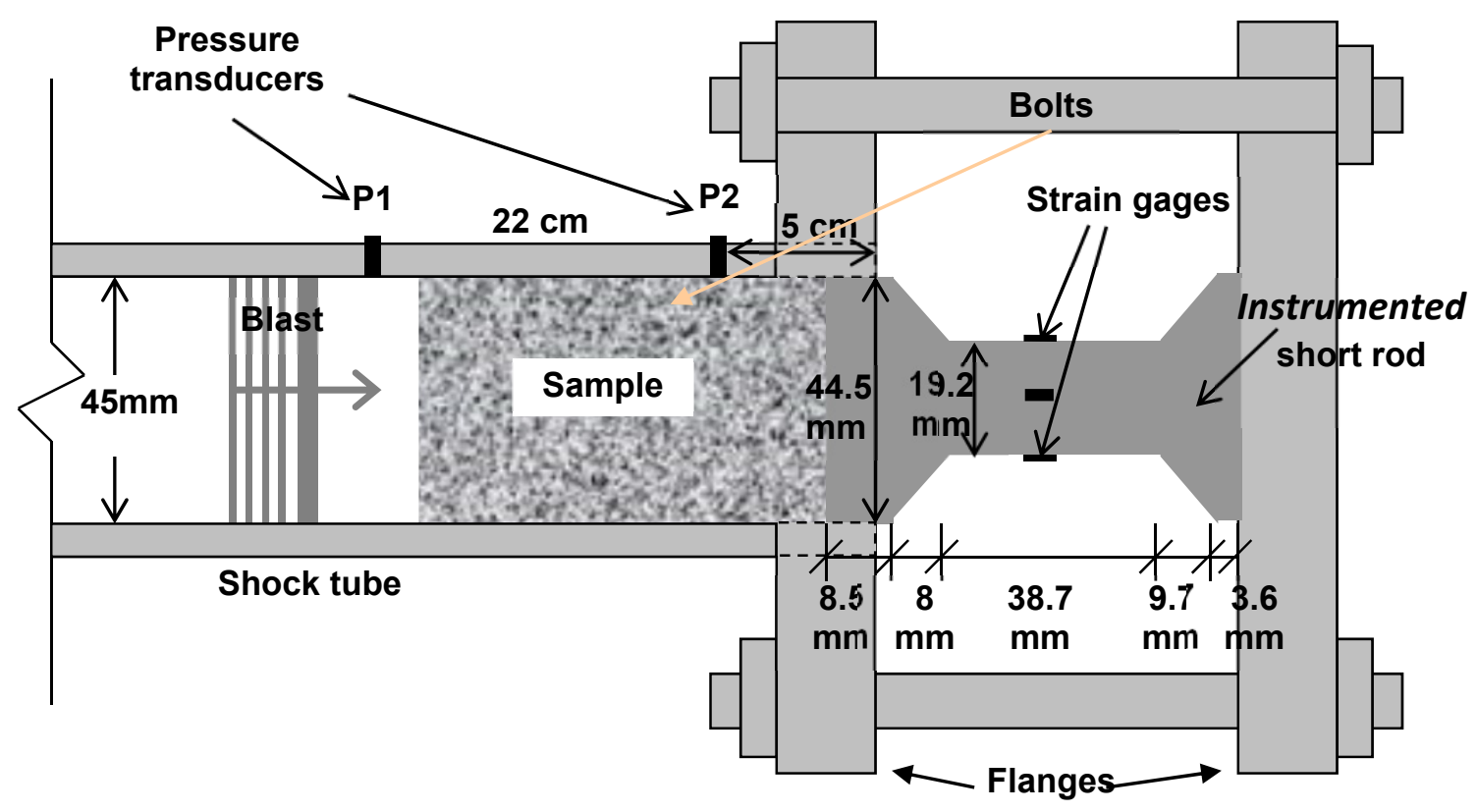

Figure 5: Schematic sketch of instrumented short rod with a stepped diameter used for measuring transmitted stress.

\section{Measurement procedure for applied blast pressure and transmitted stress}

The cellular concrete foam sample was attached to the instrumented rod using a quick setting

331 epoxy. In order to reduce friction between the outer surface of the foam sample and the wall of

332 the shock tube, the foam was wrapped with two sheets of Teflon paper. A low viscosity oil

333 (viscosity $=1 \mathrm{cps}$ ) was placed in the gap between the Teflon paper and the wall of the shock

334 tube. This was done to ensure lateral confinement to the sample during the compaction induced

335 by the blast loading and to ensure a one-dimensional state of motion of the foam. The pressure

336 sensor was used as to trigger the data acquisition.

337 Prior to putting the sample in the shock tube a ruler with markings spaced at 0.25 in.

$338(6.4 \mathrm{~mm})$ was marked on the surface using a permanent marker. All samples were photographed 
339 before and after the test. The overall change in length of sample after the test was recorded. In

340 addition, the permanent strain was determined locally between the markings of the ruler.

342 Validation of the measurement procedure and calibration of the test system

343 The response of the instrumented short rod under a triangular pulse (representing blast

344 loading) was simulated using the transient dynamic finite element analysis capability available in

345 LS-DYNA. The purpose of this exercise is to validate the procedure for obtaining the applied

346 pressure history using the measured strains from the short rod. A finite element model of a

347 quarter of the short rod was developed and meshed using Ansys ${ }^{\mathrm{TM}}$ (Version 10) as shown in

348 Figure 6. The axis of the short rod was aligned with the $\mathrm{Z}$-axis, while the $\mathrm{X}$ and the $\mathrm{Y}$ axes

349 coincided with the planes of symmetry. A triangular forcing function with an initial peak value

350 equal to $10 \mathrm{~N}$ and duration equal to $2 \mathrm{~ms}$ was applied on the all the nodes on the left face (with a

351 normal in the Z-direction). The forcing function results in a triangular pressure pulse of

$352 \mathrm{p}_{\mathrm{o}}=7.46 \mathrm{MPa}$ and $\mathrm{t}_{\mathrm{B}}=2 \mathrm{~ms}$ on the narrow segment of the short rod (with a diameter equal to

$35319.2 \mathrm{~mm}$ ) as shown in Figure 6. The other boundary conditions are such that the displacement of

354 the cross section in XZ-plane was fixed in Y direction, the displacement of the cross-section in

355 the YZ-plane was fixed in $\mathrm{X}$ direction and the displacement of the face at the right end was fixed

356 in $\mathrm{Z}$ direction. The material properties of Aluminum alloy used for the short rod were

$357=2700 \mathrm{~kg} / \mathrm{m}^{3}, \mathrm{E}=69 \times 10^{3} \mathrm{MPa}$ and Poisson's ratio $=0.3$. The Solid 174, eight node

358 quadrilateral element was used. The time step was determined as the time for the stress wave to

359 across the smallest element factored by a 'Time step scale factor', which was set to be 0.9 for

360 stability reason. The time step in the analysis was $0.15 \mathrm{~s}$. The dynamic analysis was performed 
using LS-DYNA solver incorporated in Ansys $^{\mathrm{TM}}$ (Version 10) package. The main solution methodology is based on explicit time integration [LS-DYNA theory manual 2006].

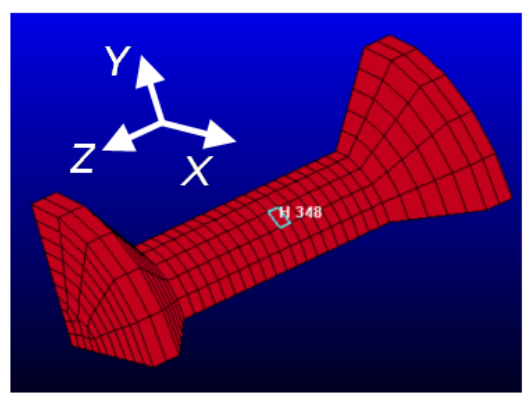

(a)

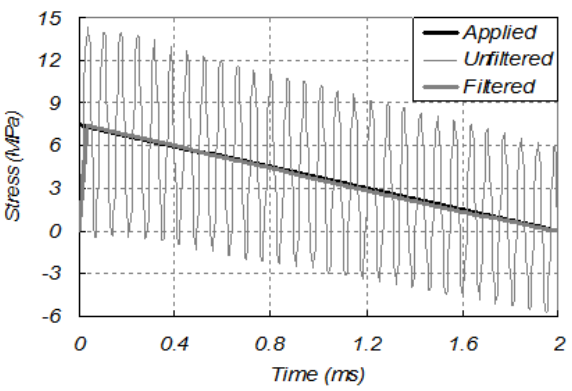

(b)

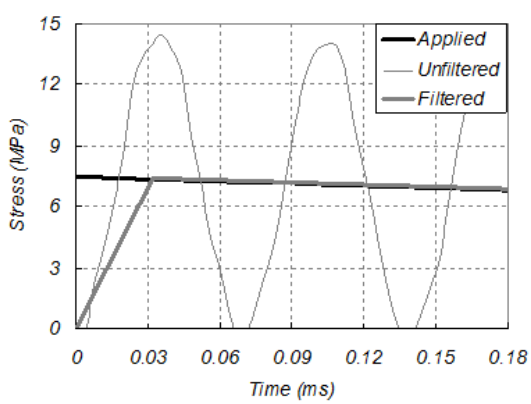

(c)

Figure 6 (a) Finite Element model of the short rod; (b) Stress history at a fixed location of the short rod due to an applied triangular pulse; Applied: applied stress at the loaded end, Unfiltered: unfiltered original stress response at the measured point and Filtered: filtered stress

The stress history of one element located on the surface of the rod, at the location corresponding to the location of the strain gauge on the specimen, is shown in Figure 6 (a). The stress response obtained from the dynamic analysis is shown in figure 6 (b). The applied pressure history is also shown in the figure for comparison. It can be seen that the stress at the specific location due to the applied triangular pulse shows a high frequency oscillatory response which is superimposed over a low frequency response with a triangular variation in time. It can also be seen that the initial stress rise produced by the wave propagation produces stress amplitude which is double of the actual applied stress. Clearly the oscillations are due to the multiple reflections of the elastic wave in the short rod, which produce a stress variation around the applied triangular pulse. The dominant period of the high frequency signal is approximately 66.6 s. The time period obtained from the numerical analysis compares favorably with the time estimated from a simple one-dimensional stress wave calculation over the length of the rod 
382 (equal to $68.5 \mathrm{~mm}$ ) considering fixed-free conditions at the two ends. The time for one complete 383 cycle for a compression wave can be estimated considering reflection at the fixed end (reflected 384 as a compression wave) followed by a phase change produced by the reflection at the free end 385 and the subsequent round trip over the full length of the rod, for the tension wave. Considering 1386 D stress compression wave speed equal to $5055 \mathrm{~m} / \mathrm{s}$, this time period can be calculated as 54.2

387 s. The low frequency response recovered from the overall response using a low-pass, moving 388 average filter over a time window equal to $66.6 \mathrm{~s}$ is also shown in Figure 6 (b). As is seen form 389 Figure 6(b), the filtered response form the short rod compares favorably with the applied stress 390 history. A close up view of the applied stress, the unfiltered stress and the filtered stress signals 391 immediately following the rise is shown in Figure 6(c). It can be seen that the actual zero rising 392 time of the onset of the applied triangular pulse has become $33 \mathrm{~s}$ for the filtered signal. This is 393 due to the use of the low-pass, moving average filter over a time window equal to $66.6 \mathrm{~s}$ on the 394 unfiltered signal.

\section{Calibration of the instrumented short rod}

The exact relationship between the recorded strain from the instrumented short rod and the stress at a given location would depend upon factors such as the gage factor of the strain gage,

399 the material constants and the geometry of the rod. Considering linear elastic behavior and linear 400 gage response, all these factors would result in a constant scaling factor for relating measured 401 strain with stress at the location. In addition, the exact relationship between the applied stress on 402 the face of the instrumented short rod and the measured stress at a given location on the rod 403 depends upon the geometry and the elastic constants of the rod. Since the measured stress is 
404 linearly related to the applied pressure, this results in an additional scaling factor, which relates 405 the measured and applied stresses. The combined effect of the geometric, material and 406 instrumentation related factors would result in a calibration factor for relating the measured 407 strain to the applied pressure, which can be determined experimentally. The stress measurement 408 system was calibrated using a blast pressure input applied directly to the instrumented short rod. 409 The pressure measured by the pressure gauges located adjacent to the front end of the 410 instrumented short rod $\left(\mathrm{P}_{2}\right.$ as shown in Figure 3$)$ corresponds to the applied stress input. The 411 strain gauge output was calibrated against the applied pressure. The measured strain can 412 therefore be converted to applied stress using the calibration factor.

413 The blast pressure loading applied on the face of the instrumented rod is shown in Figure $4147(a)$. The applied blast pressure corresponds to the reflection of an incident blast wave at the face 415 of the instrumented short rod and recorded using the pressure transducer $\mathrm{P}_{2}$, located at a distance 416 of $10 \mathrm{~mm}$ from the face. Figure 7 (b) shows the original unfiltered voltage signals obtained from 417 the strain gages attached to the short rod. The high frequency oscillations associated with the 418 wave reflections are clearly evident in the measured response (shown in the inset). The time 419 period associated with the oscillations is measured to be $64 \mathrm{~s}$, which agrees favorably with the

420 value obtained from the numerical analysis. The low-frequency component of the original signal 421 was obtained using a low-pass averaging filter with a time period equal to $64 \mathrm{~s}$ and is also 422 presented in Figure 7(b). The calibration factor for the instrumented short rod was then obtained 423 by matching the magnitude of the filtered voltage from the instrumented short rod with that of 424 the applied stress obtained from the pressure gauge. The calibration factor was applied to the 425 filtered voltage signal to give the stress history measured by the instrumented short rod and 426 shown in comparison to the applied pressure history in Figure 7(a). The stress history measured 
427 by instrumented short rod and the applied pressure history measured by the pressure transducer 428 are also shown over a shorter time interval closer to the initial rise in Figure 7(c). A good 429 comparison between two time histories is observed in Figures 7 (a) and (c). The calibration using 430 a real blast pressure wave shows that the measurement procedure provides an accurate estimate 431 of the applied pressure history and the initial shock front is adequately resolved.

432

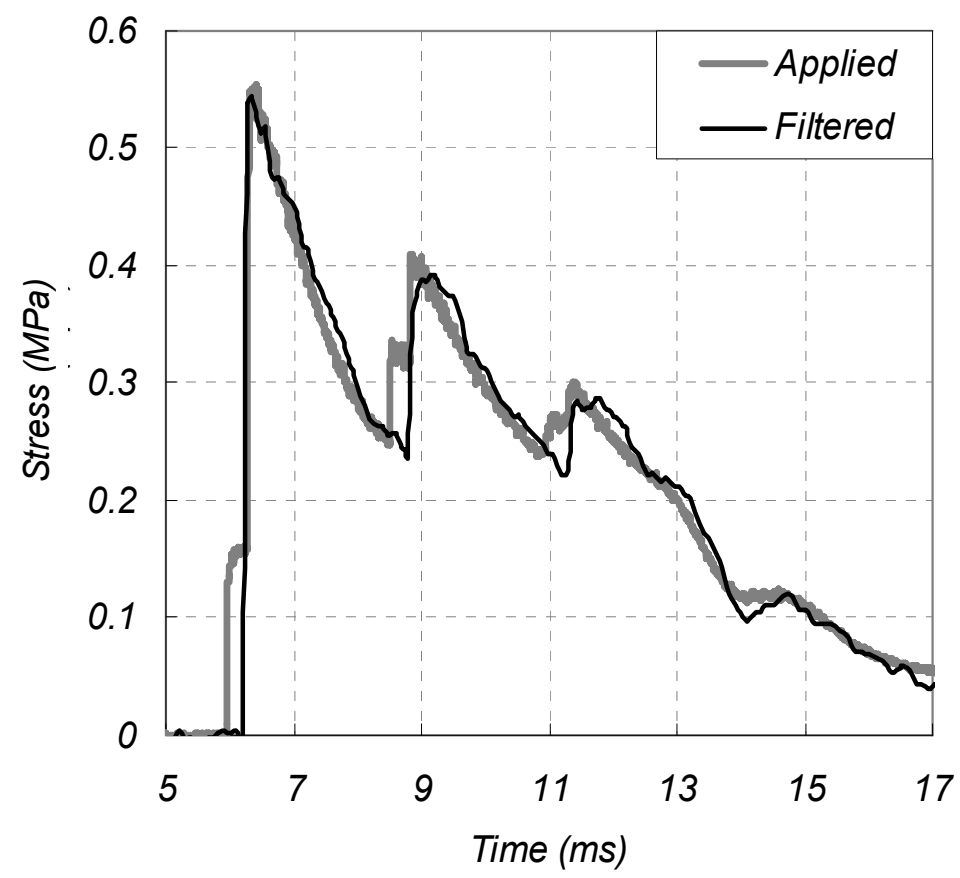

433

(a)

434 


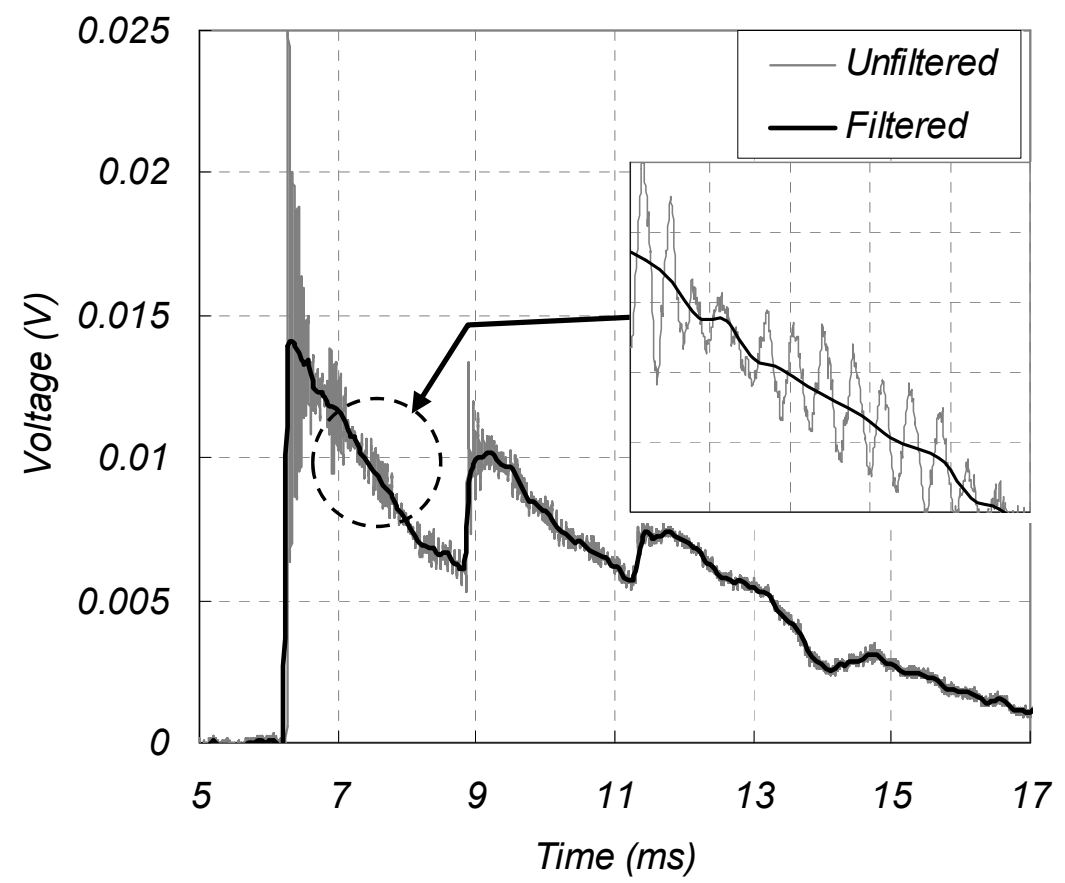

(b)

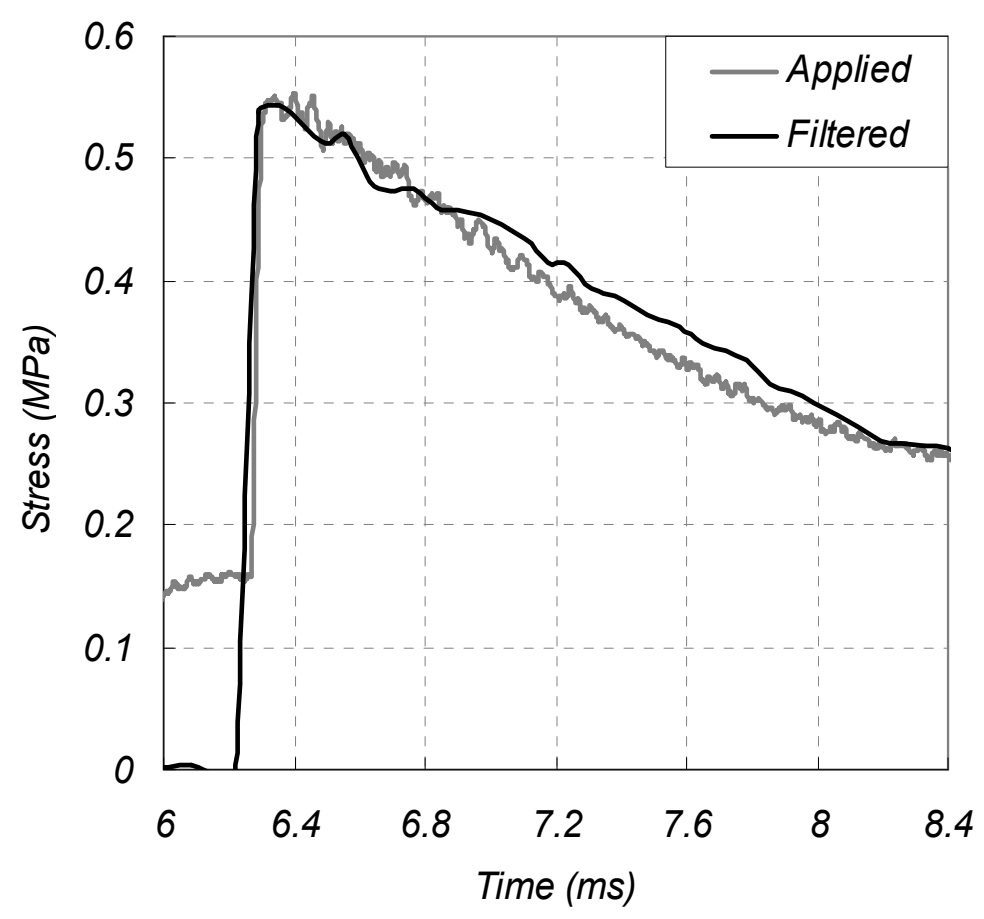

(c)

Figure 7 Stress history recorded by the instrumented short rod when a blast wave strikes directly on it. (a) Applied pressure and calibrated filtered stress and (b) unfiltered and filtered signal from strain gages in voltage and (c) the close up view of the applied pressure and calibrated filtered stress. 
Comparisons between the calibrated stress signals from the instrumented short rod and the

443 applied pressure for different blast pressure loads are shown in Figures 8 (a) and (b). The

444 calibration constant determined from the results in Figure 7 was applied to the cases shown in

445 Figures 8(a) and (b). The direct blast pressure measurements provide a validation for that the 446 applied stress measurement using the calibrated strain measurements obtained from the short 447 stepped rod.

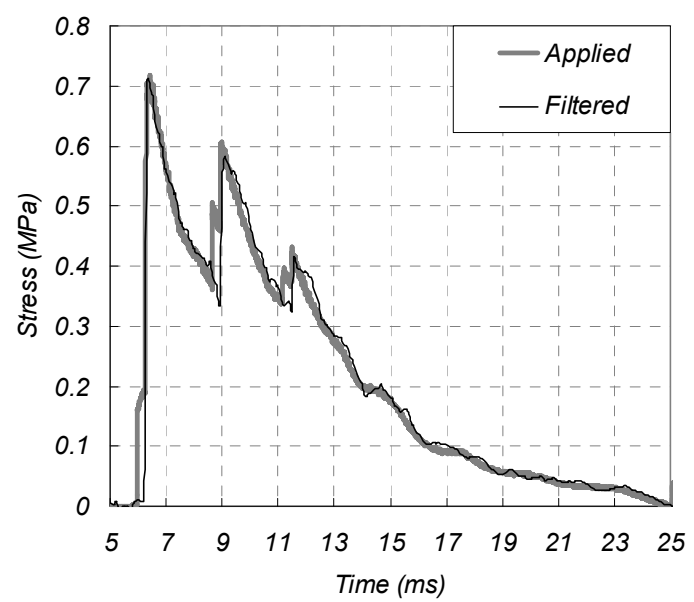

(a)

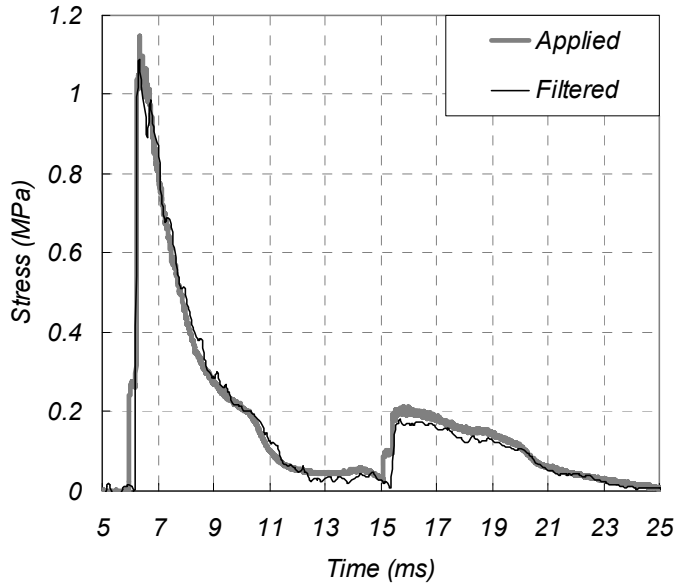

(b)

Figure 8 (a) and (b): the applied pressure from the pressure transducer compared to the calibrated filtered stress from the instrumented short rod under different blast loads.

452

453

\section{Experimental Results with Cement Foam}

The results showing the applied and transmitted stress for $384 \mathrm{~kg} / \mathrm{m}^{3}$ and $480 \mathrm{~kg} / \mathrm{m}^{3}$ density

455 foams are given in Figures 9 (a) and 9 (b), respectively. For each density, samples of varying 456 length were subjected to blast pressure loadings of nominally similar amplitudes and durations.

457 For the $384 \mathrm{~kg} / \mathrm{m}^{3}$ density foam, samples with three different lengths, $\mathrm{L}=230 \mathrm{~mm}, 152 \mathrm{~mm}$ and $458102 \mathrm{~mm}$ (designated as long, mid and short in Figure 9 (a)) were used in the test program. For 
459 the $480 \mathrm{~kg} / \mathrm{m}^{3}$ density foam, foam samples of lengths, $\mathrm{L}=184 \mathrm{~mm}, 127 \mathrm{~mm}$ and $76 \mathrm{~mm}$ 460 (designated as long, mid and short in Figure 9 (b)) were used in the test program. In all tests, the 461 applied blast pressure amplitudes are comparable and nominally equal to $1.3 \mathrm{MPa}$, which is 462 greater than the crushing stress of the foam; po is equal to $0.384 \mathrm{MPa}$ and $0.66 \mathrm{MPa}$ for foams 463 with densities $384 \mathrm{~kg} / \mathrm{m}^{3}$ and $480 \mathrm{~kg} / \mathrm{m}^{3}$, respectively. From the results for both cement foams, it 464 is immediately obvious that the transmitted stress depends upon the length of foam samples. 465 Considering the response from the samples of the largest length for foam samples of both 466 densities, the applied blast pressure loading is transmitted as a stress pulse of rectangular shape 467 characterized by a nominally constant stress of a magnitude smaller than the applied pressure. 468 The rectangular pulse has amplitude approximately equal to, but slightly higher than the crushing 469 strength of the foam. As the length is decreased, there is an increase in the magnitude of stress, 470 which follows the initial constant transmitted stress. The increase in the transmitted stress is very 471 significant in the samples with shortest length; the transmitted stress amplitude is higher than the 472 applied blast pressure amplitude producing stress enhancement for this case. The results indicate 473 that when the length of the foam samples is sufficiently long there is a complete attenuation of 474 the applied blast pressure to a stress level, which is slightly higher than the crushing strength of 475 the foam. The length of the foam required to attenuate a given blast signal depends upon the 476 crushing strength of the foam. On decreasing the length, there is an increase in the amplitude of 477 transmitted stress. This suggests that there is a critical length of the foam $\left(\mathrm{L}_{\mathrm{cr}}\right)$, which depends 478 upon its crushing strength, which is required to completely attenuate the applied blast pressure 479 loading. For the applied blast pressure loading, $\mathrm{L}_{\mathrm{cr}}$ for the $384 \mathrm{~kg} / \mathrm{m}^{3}$ foam is smaller than $480230 \mathrm{~mm}$ but larger than $152 \mathrm{~mm}$. Similarly, for the $480 \mathrm{~kg} / \mathrm{m}^{3}$ foam, $\mathrm{L}_{\mathrm{cr}}$ is smaller than $178 \mathrm{~mm}$ 481 but larger than $127 \mathrm{~mm}$. 
When the length of sample is less than $\mathrm{L}_{\mathrm{cr}}$, the transmitted stress amplitude exceeds the 483 crushing strength of the foam. When the length of the foam is significantly smaller than $\mathrm{L}_{\mathrm{cr}}$, the

484 results indicate that there is a significant a stress enhancement, where the transmitted stress with

485 the foam is higher than the stress directly applied by the blast pressure loading. This suggests

486 that there is a minimum threshold length of the foam $\left(\mathrm{L}_{\mathrm{th}}\right)$, smaller than $\mathrm{L}_{\mathrm{cr}}$, below which there is

487 a stress enhancement to a value higher than the applied blast pressure amplitude. For the applied

488 blast pressure loading, $\mathrm{L}_{\text {th }}$ for the $384 \mathrm{~kg} / \mathrm{m}^{3}$ foam is in the range $\{152 \mathrm{~mm}, 102 \mathrm{~mm}\}$ and for the $489480 \mathrm{~kg} / \mathrm{m}^{3}$ foam in the range $\{127 \mathrm{~mm}, 76 \mathrm{~mm}\}$.

490

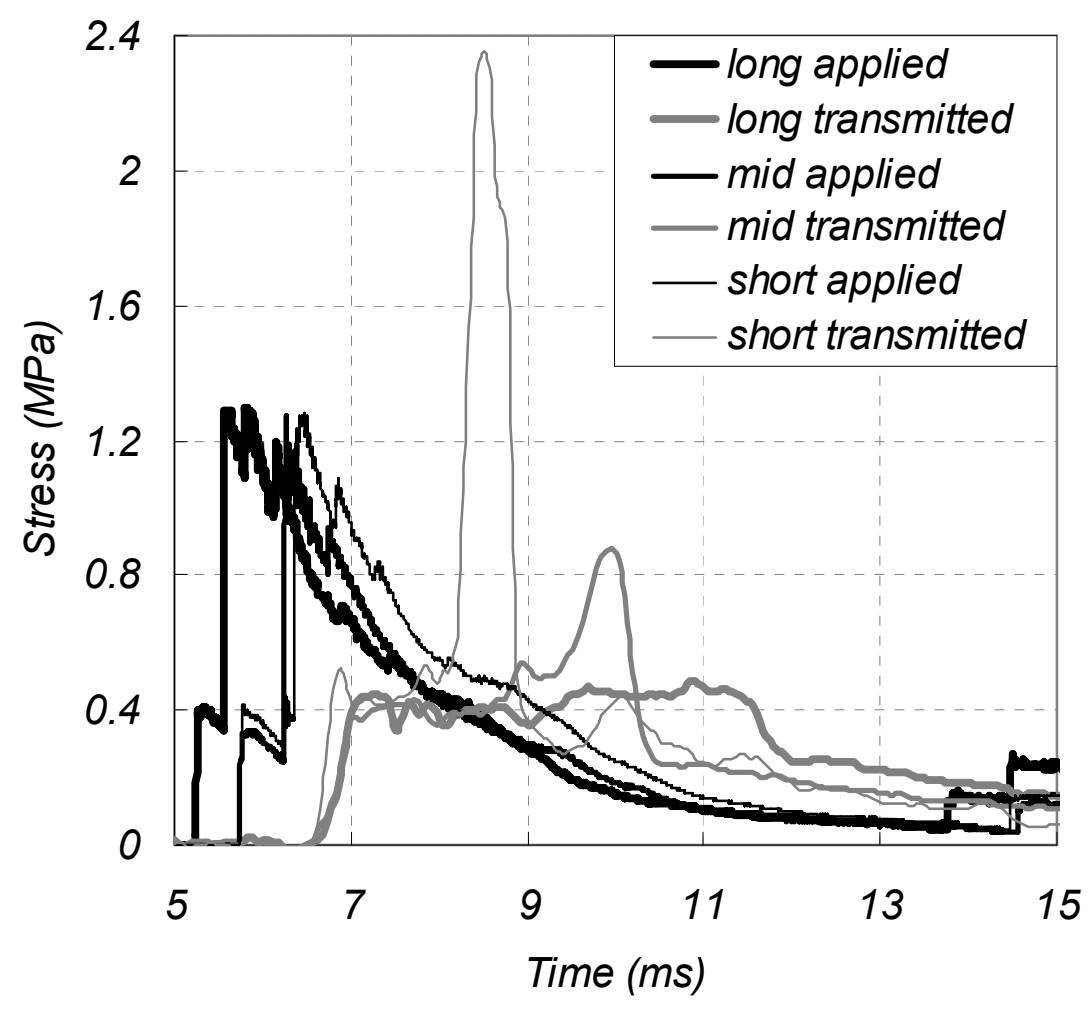




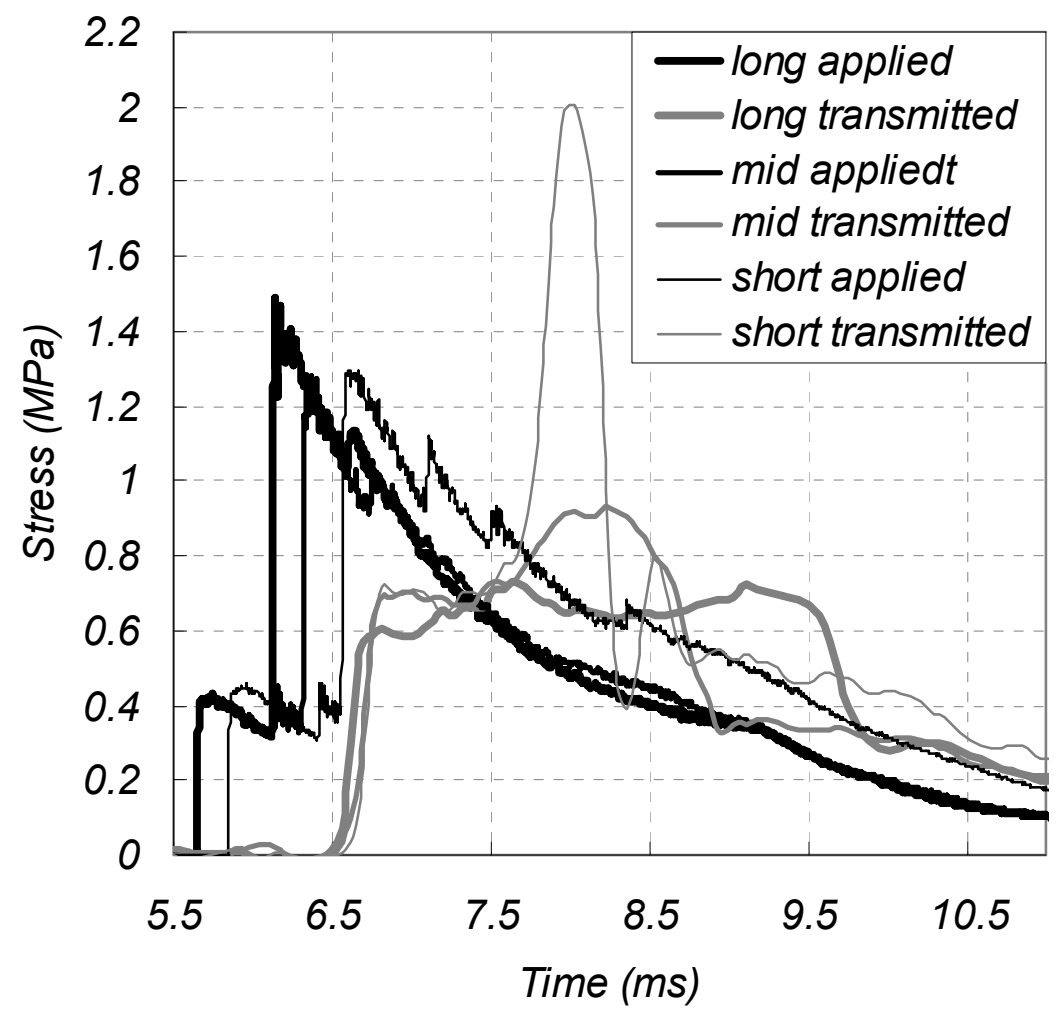

(b)

Figure 9: Applied blast pressure versus the transmitted stress subjected to similar blast loadings with different samples lengths (long/medium/short) for cellular concrete of the two densities, (a) lengths $230 \mathrm{~mm} / 152 \mathrm{~mm} / 102 \mathrm{~mm}$ for $384 \mathrm{~kg} / \mathrm{m}^{3}$ and (b) lengths $184 \mathrm{~mm} / 127 \mathrm{~mm} / 76 \mathrm{~mm}$ for $480 \mathrm{~kg} / \mathrm{m}^{3}$.

\section{Analysis of Compacted Foam}

Irreversible volumetric contraction was observed in all samples subjected to blast pressure loading. There was compaction of the material along the length of the sample, which was produced by the crushing of the cells. The length of the material compacted however, varied with the initial length of the sample. In samples of length larger than $\mathrm{L}_{\mathrm{cr}}$, compaction and crushing of cells was observed in material at both the loaded end and the transmission end. The material in 
505 the middle portion, away from the ends, was found to be relatively intact. In samples with length 506 smaller than $\mathrm{L}_{\mathrm{cr}}$, compaction and crushing of cells was observed over the entire length of the 507 foam samples.

508 Typical photographs of foam samples before and after testing are shown in Figures 10 and 50912 , respectively for the $184 \mathrm{~mm}$ and the $76 \mathrm{~mm}$ samples made with the $480 \mathrm{~kg} / \mathrm{m}^{3}$ density foam. 510 For each sample, two opposite faces are photographed. In Figure 10, the initial length of the 511 sample was, $\mathrm{L}=184 \mathrm{~mm}$. In Figure 12, the initial length of the sample, $\mathrm{L}=76 \mathrm{~mm}$. The 512 engineering strain of the compacted foam along the length of the sample was obtained using the 513 distance between two adjacent markings in the compacted material and is shown in Figures 11 514 and 13. In Figure 11 (184 $\mathrm{mm}$ long foam sample), it is observed that at the loaded end $80 \mathrm{~mm}$

515 foam is compacted with an irreversible strain equal to 0.45 , and $60 \mathrm{~mm}$ foam is compacted at the 516 transmitted end with an irreversible strain approximately equal to 0.3 . The region between the 517 two compacted portions remains relatively un-deformed. The result indicates that $184 \mathrm{~mm}$ is 518 sufficient to attenuate the applied blast wave and it is larger than $\mathrm{L}_{\mathrm{cr}}$ for the applied blast loading.

519 In Figure 13 (76 $\mathrm{mm}$ cement foam), it is observed that at the entire foam is compacted and the 520 average irreversible strain reaches up to 0.6 . Therefore, the $76 \mathrm{~mm}$ does not provide sufficient 521 length required to fully attenuate the applied blast pressure loading. Further, for length of foam 522 significantly smaller than $\mathrm{L}_{\mathrm{cr}}$ there is significant compaction of the foam, which is uniform 523 across the length of the foam. The strain in the foam is in the densification part of the stress524 strain response of the material. Therefore, $\mathrm{L}_{\text {th }}$ would represent the minimum length which would 525 produce uniform compaction over the entire length of the foam to a value in the densification 526 region of the foam. 


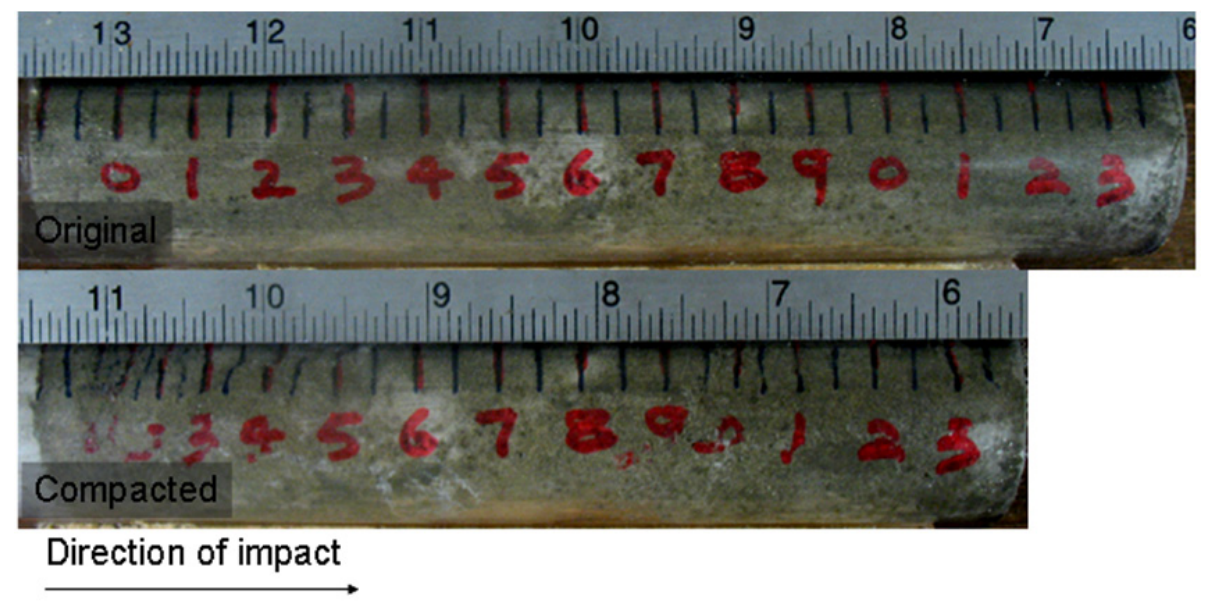

(a)

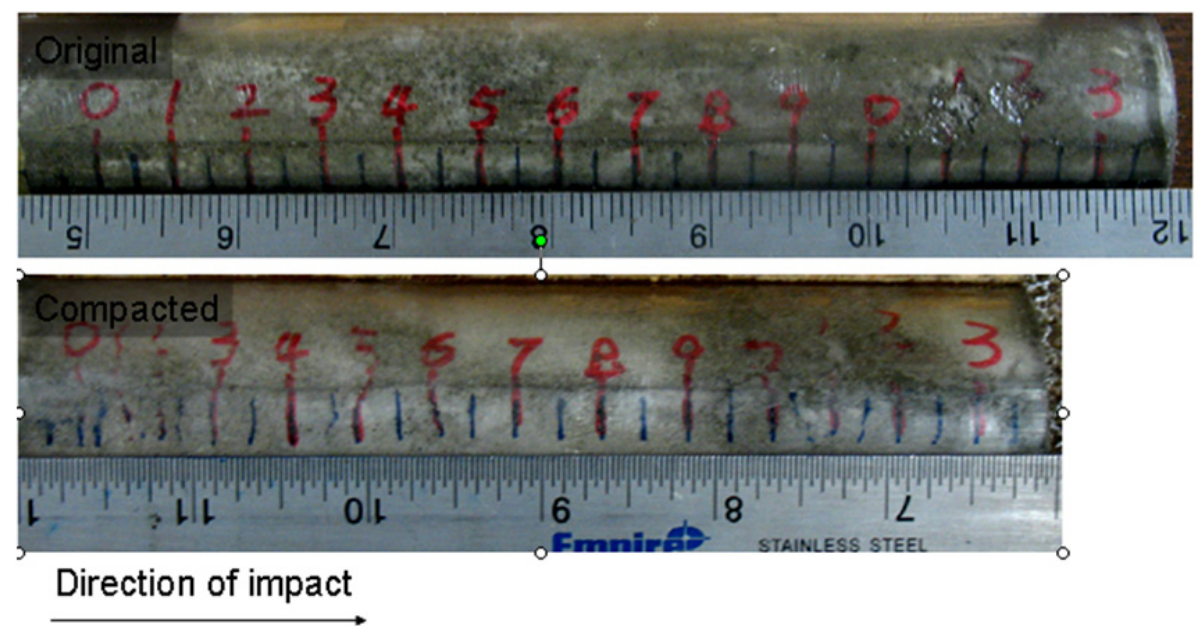

(b)

531 Figure 10: Deformation of $L=184 \mathrm{~mm}$ sample made with the $480 \mathrm{~kg} / \mathrm{m}^{3}$ cement foam before and after compaction ( $L>L_{c r}$ case), (a) face 1 and (b) face 2. 


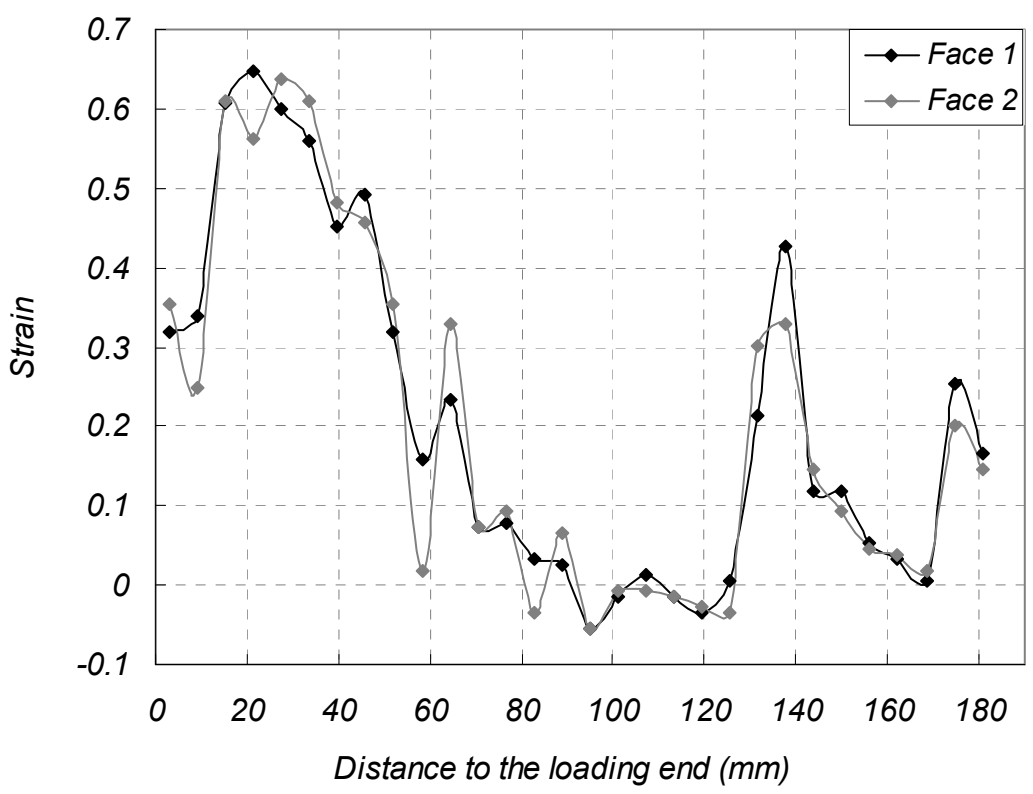

534 535 536

Figure 11: Engineering strain after compaction measured from Figure 10 for the foam with stress response shown in Figure 9
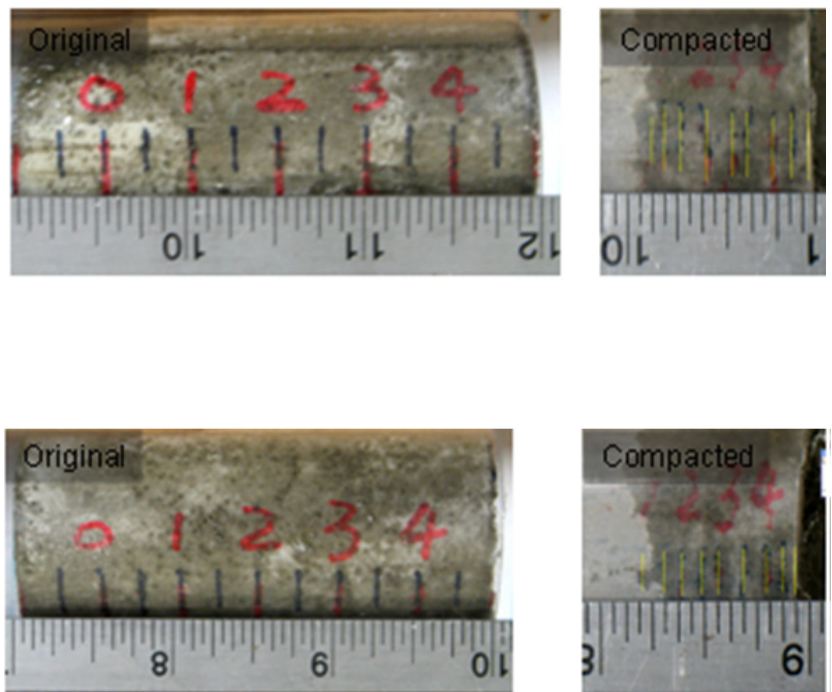

(a)

(b)

Figure 12: Deformation of $L=76 \mathrm{~mm}$ sample made with the $480 \mathrm{~kg} / \mathrm{m}^{3}$ cement foam before and after compaction ( $L<L_{\text {th }}$ case), (a) face 1 and (b) face 2. 


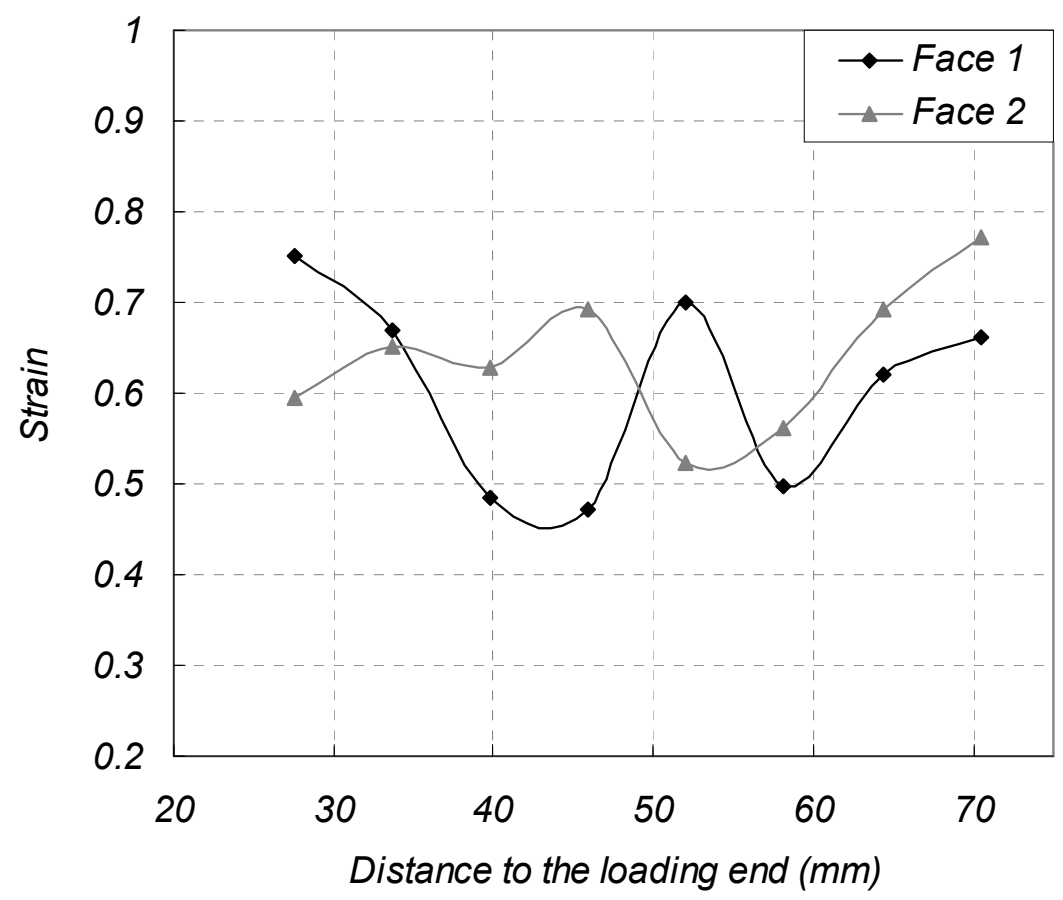

541

542

543

544

545

546

547

548

549

550

551

552 produces compaction of the cellular concrete immediately below the point of application of the 553

554
Figure 13: Engineering strain after compaction measured from Figure 12 for foam with stress response shown in Figure 9.
Discussion

The observed experimental response can be explained considering propagation of the stress waves through the cellular concrete. When the applied blast pressure wave produces an increase in stress at the loaded end beyond the crushing strength of the foam, stress wave(s) of different magnitudes are produced in the cellular concrete. An elastic wave which propagates at a speed predicted by the initial elastic modulus of the material travels into the material. Since the initial applied pressure amplitude is higher than the crushing strength of the cellular concrete, it also applied stress. Two waves are thus formed in the material: (a) A faster elastic stress wave with amplitude equal to the crushing strength of cellular concrete; and (b) A slower compaction front, 
555 which produces densification of material in its wake. The elastic wave travels with constant 556 amplitude as it propagates in the material. As the compaction front propagates in the material, 557 there is a continuous decrease in its amplitude due to the energy dissipation provided by 558 irreversible compaction of the foam. When the amplitude of the compaction front decreases to a 559 value equal to the crushing strength of the cellular concrete, compaction of the material stops.

560 The elastic wave propagates in the material and when it reaches the back end, reflection produces 561 wave(s) travelling in the backward direction. There is an increase in the stress upon reflection 562 from a substrate of higher stiffness; the stress increases above the crushing strength of foam. The 563 stress transmitted to the substrate, which corresponds to the amplitude of the reflected pressure is 564 therefore higher than the crushing strength of the foam. An elastic wave and a compaction front 565 travelling in the reverse direction are produced after reflection. The compaction front produces 566 densification till attenuation produced by compaction reduces its amplitude to the crushing 567 strength of cellular concrete. The stress waves produced in the foam therefore produce 568 compaction at both the front and the back ends of the foam. When sufficient length of foam is 569 available, the material away from the ends remains uncompacted. The transmitted stress from the 570 foam in this case is nominally higher than the crushing strength of the foam, since the reflection 571 of the elastic wave of magnitude equal to the crushing strength, upon reflection from a substrate, 572 which is stiffer than the foam produces a wave of magnitude larger than the incident wave.

573 In the case when the length of the foam is insufficient to completely attenuate the 574 compaction wave produced by the incident blast pressure wave, the initial elastic wave of 575 magnitude given the crushing strength of foam upon reflection from the substrate produces stress 576 waves travelling back into the uncompacted foam. Since the stress rises above the crushing 577 strength, both an elastic wave and a compaction front are produced. Subsequent stress history at 
578 the transmitted end is a result of a forward travelling compaction produced by the applied blast

579 pressure loading and an elastic wave and a compaction front travelling in the reverse direction

580 produced by the reflection of the elastic wave front from the back end. The reflection of the

581 compaction front travelling in compacted material, from the back end results in a stress rise, the

582 magnitude of which depends on the magnitude of the incident stress wave, densities of the

583 material compacted foam and substrate and state of compaction of foam.

584 In a material which exhibits concave stress-strain response, the existence of the minimum

585 length of material to attenuate the initial compaction front has previously been predicted using

586 simplified a rigid-perfectly-plastic-locking (RPPL) idealization of the actual stress-strain

587 response [Li and Meng 2002, Ma and Ye 2007, Nian et al. 2012]. In the RRPL idealization, the

588 crushing and densification of the material occurs at a constant value of stress up to a fixed value

589 of strain, following which the material exhibits a rigid behavior. The minimum length of the

590 cellular concrete required to completely attenuate the applied blast pressure wave as it

591 propagates down the length of the material, which is equal to the length of compacted foam on

592 the front end, depends upon the impulse of the blast pressure wave and the crushing strength of

593 the foam. The length of the cellular foam increases with an increase in the applied blast pressure

594 impulse and decreases with the increase in the crushing strength of the material. The theoretical

595 calculation shows that compaction ends when the impulse of the applied blast pressure wave

596 equals the impulse of the transmitted stress wave with amplitude equal to the crushing strength

597 of the material [Nian et al. 2015]. The experimental results indicate that the impulse of the 598 applied blast pressure wave is conserved. The transmitted stress wave in the instrumented steel 599 rod at the back end has the same impulse as the applied blast pressure loading [Nian et al. 2015]. 600 Application of foams for blast protection applications therefore requires careful 
601 consideration. A low-strength foam can decrease the amplitude of the transmitted stress provided

602 the length is larger than the critical length. For an applied blast pressure loading, if length is

603 smaller than the critical length, the stress enhancement produced by the foam can increase

604 beyond stress produced by direct incidence of the blast pressure on the substrate.

605

606 Summary and Findings

607 The results of the experimental investigation clearly show that for each applied blast

608 pressure loading, there exists a critical length of cement foam, $\mathrm{L}_{\mathrm{cr}}$, which depends upon the 609 cement foam density. When $\mathrm{L}>\mathrm{L}_{\mathrm{cr}}$, the blast load applied to the foam bar is transformed into a

610 rectangular stress pulse at the target end. The magnitude of the transmitted stress is nominally

611 equal to the crushing strength of cement foam, po, which is less than the peak blast pressure $\mathrm{P}_{\mathrm{o}}$,

612 and therefore the cement foam reduces the peak stress delivered to the solid substrate to be

613 protected. In $\mathrm{L}>\mathrm{L}_{\mathrm{cr}}$ cases the compaction wave diminishes before reaching the solid substrate.

614 The first rise and subsequent plateau of the transmitted stress is generated by the reflection of

615 elastic precursor at the right boundary, the amplitude of which is solely determined by the

616 characteristic of foam and is irrespective of the blast load. The amplitude is theoretically equal to

617 po plus an overpressure $\Delta c$ associated with the reflection of elastic precursor but $\Delta c$ is

618 typically negligible for foam type material.

619 When $\mathrm{L}<\mathrm{L}_{\mathrm{cr}}$, there is a stress enhancement, where a second jump in the magnitude of the 620 transmitted stress follows the initial rectangular shaped stress pulse. The stress enhancement is

621 caused by the reflection of the compaction front from the surface of the substrate. If the length of

622 the foam is significantly smaller than the required $\mathrm{L}_{\mathrm{cr}}$, the compaction in the material could reach

623 a value in the densification phase of the stress-strain curve and the stress enhancement can be 
624 higher than the applied blast pressure amplitude.

625

626 Acknowledgements

627 The authors would like to acknowledge support from the National Science Foundation (Grant

628 No. CMMI -0800307) during this study.

629

630 


\section{References}

632 1. Ben-Dor G., Mazor G., Igra O., Sorek S. and Onodera H., Shock wave interaction with 633 cellular materials, Part II: open cell foams; experimental and numerical results. Shock Waves, $634 \quad 1994,3: 167-79$.

635 2. Cooper G.J., Townend D.J., Cater S.R., Pearce B.P., The role of stress waves in thoracic 636 visceral injury from blast loading: modification of stress transmission by foams and high-

637 density materials. Journal of Biomechanics 1991, 24(5):273-85.

638 3. Courant R., Friedrichs K.O., Supersonic flow and shock waves, Springer-Verlag 1976.

639 4. Guruprasad S. and Mukherjee A., Layered sacrificial claddings under blast loading. Part II 640 Experimental studies. International Journal of Impact Engineering, 2000, 24: 975-984

641 5. Gibson, L.J., and Ashby, M.F., Cellular Solids - Structures and Properties, Progress Press, $642 \quad$ Oxford, England 1999

643

644

645

646

647

648

649

650

651

652

653

654

6. Gvozdeva L. G., Faresov Yu. M. and Fokeev V. P., Interaction of air shock waves with porous compressible materials. Journal of Applied Mechanics and Technical Physics, 1985, 26(3): 401-405.

7. Hallquist J.O., LS-DYNA Theoretical Manual, Livermore Software Technology Corporation, Livemore, California, 1998.

8. Hanssen, A.G., L. Enstock, and M. Langseth, Close range blast loading of aluminium foam panels, International Journal of Impact Engineering, 2002, 27: 593-618.

9. Hoff, G.C., New Application for Low-Density Concretes, ACI SP 29-11, 1971, 29: 181-220.

10. Kaiser M.A., Advancements in the Split Hopkinson Bar Test. M.S. Thesis, Department of Mechanical Engineering, The Virginia Polytechnic Institute and State University 1998

11. Kamyab W., Subramaniam K.V., Andreopoulos Y., Stress Transmission in Porous Materials Impacted by Shock Waves, Journal of Applied Physics, 2011, 109: 013523. 
655 12. Levy A., Ben-Dor G., Skews B. W. and Sorek S., Head-on collision of normal shock waves 656 with rigid porous materials. Experiments in Fluids, 1993, 15: 183-190.

657 13. Levy A., Sorek S., Ben-Dor G. and Bear J., Evolution of the balance equations in saturated 658 thermoelastic porous media following abrupt simultaneous changes in pressure and 659 temperature. Transport in Porous Media, 1995, 21: 241-268.

660 14. Li Q.M. and Meng H., Pressure-Impulse Diagram for Blast Loads Based on Dimensional 661 Analysis and Single-Degree-of-Freedom Model, Journal of Engineering Mechanics, 2002, $662 \quad 128(1): 87-92$

663 15. Ma G.W., and Ye Z.Q., Analysis of foam claddings for blast alleviation, International 664 Journal of Impact Engineering 2007, 34 (2007) 60-70

665 16. Monti R., Normal shock wave reflection on deformable solid walls. Mechanica 1970, 4: 285666296.

667 17. Nian W., Subramaniam K.V., and Andreopoulos, Y., Dynamic compaction of foam under 668 blast loading considering fluid-structure interaction effects, International Journal of Impact $669 \quad$ Engineering, 2012, 50: 29-39.

670 18. Nian W., Subramaniam K.V.L., and Andreopoulos Y., Experimental Investigation of Blast 671 Pressure Attenuation by Cellular Concrete, Materials Journal, ACI, 2015, 112(1): 21-28.

672 19. Nian W., Subramaniam K.V.L., and Andreopoulos Y., One-Dimensional Numerical 673 Framework for Shock Compaction of Cellular Foams, Journal of Aerospace Engineering, $674 \quad$ ASCE, 2016, (doi: 10.1061/(ASCE)AS.1943-5525.0000576)

675 20. Reid S. and Peng C., Dynamic uniaxial crushing of wood. International Journal of Impact $676 \quad$ Engineering, 1997, 19: 531-570. 
677 21. Skews B.W., The reflected pressure field in the interaction of weak shock waves with a $678 \quad$ compressible porous foams. Shock Waves, 1991, 1: 205-211.

679 22. Skews B.W., Atkins M.D., and Seitz M.W., The impact of shock wave on porous 680 compressible foams. Journal of Fluid Mechanics, 1993, 253: 245-265.

681 23. Tan P.J., et al., Dynamic compressive strength properties of aluminum foams. Part I682 experimental data and observations. Journal of the Mechanics and Physics of Solids, 2005, $683 \quad 53: 2174-2205$.

684 24. Standley E., Umnova O., Attenborough K., and Dutta P., Shock Wave Reflection 685 Measurements on Porous Materials. Noise Control Eng., 2002; 50(6): 224-230

686 25. Subramaniam K.V., Nian W., and Andreopoulos Y., Blast Response Simulation of an Elastic 687 Structure: Evaluation of the Fluid-Structure Interaction Effect, International Journal of 688 Impact Engineering, 2009, 36(70): 965-974. 